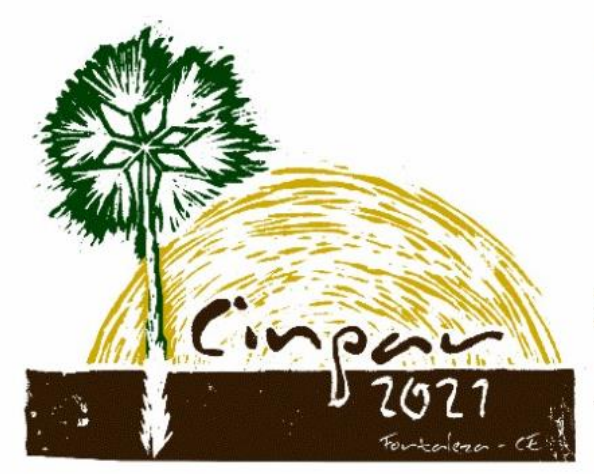

XVII Congresso Internacional sobre Patologia e Reabilitação das Construções

XVII Congreso Internacional sobre Patología y Rehabilitación de las Construcciones

XVII International Conference on Pathology and Constructions Rehabilitation

FORTALEZA (Brasil), 3 a 5 de junho de 2021 https://doi.org/10.4322/CINPAR.2021.149

\title{
Adequação de treliça em aço frente a uma nova finalidade
}

\author{
Gustavo Oliveira Daumas ${ }^{(1)}$, José Geraldo de Araújo Silva ${ }^{(2)}$, Lucas Teixeira Araújo ${ }^{(3)}$, \\ Antônio Maria Claret de Gouveia ${ }^{(4)}$, Hisashi Inoue ${ }^{(5)}$, André Luiz Candian ${ }^{(6)}$, \\ (1) Gustavo de Oliveira Daumas, Instituto Tecnológico da Aeronáutica, Brasil. \\ Email:godaumas@gmail.com \\ (2) MSc José Geraldo de Araújo Silva, Engenheiro Civil, Metalcon, Brasil. \\ Email:igaraujo@gmail.com \\ (3) Lucas Teixeira Araújo, Universidade Federal de Ouro Preto, Brasil. \\ Email: lucastexeira32@gmail.com \\ (4) Dr. Prof. Antônio Maria Claret de Gouveia, Universidade Federal de Ouro Preto, Brasil. \\ Email: amcgouveia@gmail.com \\ (5) Dr. Prof. Hisashi Inoue, Universidade Federal de São João Del Rei, Brasil. \\ Email: hisashi@ufsj.edu.br \\ (6) MSc André Luiz Candian, Engenheiro Civil, Faculdade Única, Brasil. \\ Email:alcandian@gmail.com
}

Resumo: Durante a existência de uma edificação/estrutura é normal que, devido a alterações normativas e/ou necessidades de produção e de utilização, que a mesma seja modificada para atender aos esforços oriundos das novas cargas. Isto não quer dizer que ocorrera erro de projeto, fabricação ou montagem, mas sim que a estrutura esteja apenas sendo adequada a uma nova condição, sendo portanto necessária a realização de novo dimensionamento, elaboração de projeto de reforço e colocação dos novos elementos estruturais.

Para os casos em que a necessidade de aumento de carga seja pequena, estando abaixo dos fatores normativos, é aceitável, dependendo da experiência e acurácia do calculista/fabricante que não sejam feitos reforços, mas via de regra, esta não é a praxe. De uma maneira geral os responsáveis pelos processos de reforço/adequação estrutural devem ter expertise suficiente para discernir até a que ponto podem chegar sem colocar em risco a segurança estrutural, quer seja pela utilização ou pelo serviço.

Este trabalho apresenta todo o processo de adequação de uma treliça metálica estaiada, utilizada como pipe rack, tendo dois balanços atirantados e um vão central, também atirantado, assemelhando-se à famosa ponte do Brooklin em Nova York. Após a ocorrência de um sinistro (queda de uma árvore durante uma ventania, que veio a colapsar a estrutura em seu vão central) optou-se por alterar a localização e tipologia estrutural do novo pipe rack (aproveitando parte da estrutura colapsada), passando o mesmo a ser em treliça isostática. Esta ação alterou sobremaneira os esforços atuantes na estrutura, sendo necessário propor diversos reforços e trocar algumas peças para que a treliça ficasse simétrica.

Palavras-chave: Sinistro estrutural, Reforço estrutural, Treliça metálica, Treliça atirantada, Estrutura atirantada 


\section{Introdução}

Por mais estranho que possa parecer, toda e qualquer estrutura, quer seja uma edificação simples, ponte ou cobertura metálica, deve ser tratada como um ser vivo, pois durante a "sua vida" ela sofre com as intempéries (sol, chuva e vento) e com as cargas de utilização, sendo necessária a realização de intervenções (corretivas ou não) visando a manutenção das características originais da estrutura, a fim de que ela possa continuar exercendo a função para qual fora projetada e construída.

Da concepção até a utilização, passando pela execução, alterações de finalidade, patologias ou as built, todas as fases merecem atenção para que nenhuma não conformidade e/ou desvio passem despercebidos, pois isto poderá gerar graves problemas no futuro.

Algo muito importante e que por vezes não é considerado é a localização de uma estrutura/edificação, ou seja, como está o entorno da futura obra, pois dependendo da condição, problemas poderão surgir, quer seja pelo deslizamento de encostas, enchentes ou afunilamento de vento.

A elaboração de um manual de uso da estrutura juntamente com um memorial descritivo é de suma importância para que, durante a existência da mesma, todos as intervenções que se façam necessárias sejam realizadas dentro de uma conceituação lógica e coerente, a fim de que não ocorram efeitos indesejados e/ou o que devia ser um reparo, torne-se um novo problema.

Na iminência da ocorrência de um problema ou mesmo quando este já estiver ocorrido, para que se obtenha uma melhor performance na intervenção é imperativo que esta seja realizada o quanto antes, pois quando se intervêm de imediato, as possibilidades de sucesso são enormes. As razões para tal é que neste caso tem-se mais tempo para procurar soluções; o problema pode ainda estar no início e as cobranças pela volta à normalidade ainda não estão em nível estressante.

A estrutura inicial era constituída de uma treliça $3 d$, estaiada, utilizada para travessia de um rio, tendo tubulações de produto químico em sua parte inferior e superior ( 3 tubos em PEAD com diâmetro de $500 \mathrm{~mm}$ ). Os pilares para suporte dos tirantes eram em concreto armado.

As dimensões da estrutura são:

Comprimento total: 130 metros

Balanço à esquerda: $20 \mathrm{~m}$

Vão central: $90 \mathrm{~m}$

Balanço à direita: $20 \mathrm{~m}$

Altura: $3.50 \mathrm{~m}$

Largura: $3.00 \mathrm{~m}$

Modulação: $5.00 \mathrm{~m}$

Banzos: perfil dobrado a frio $250 \times 75 \times 6.3 \times 25$, em aço USI-SAC41 (de projeto) 


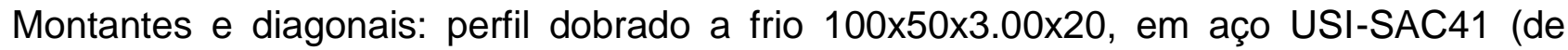
projeto)

As Figuras 1 e 2 apresentam a vista lateral e o corte transversal da estrutura.

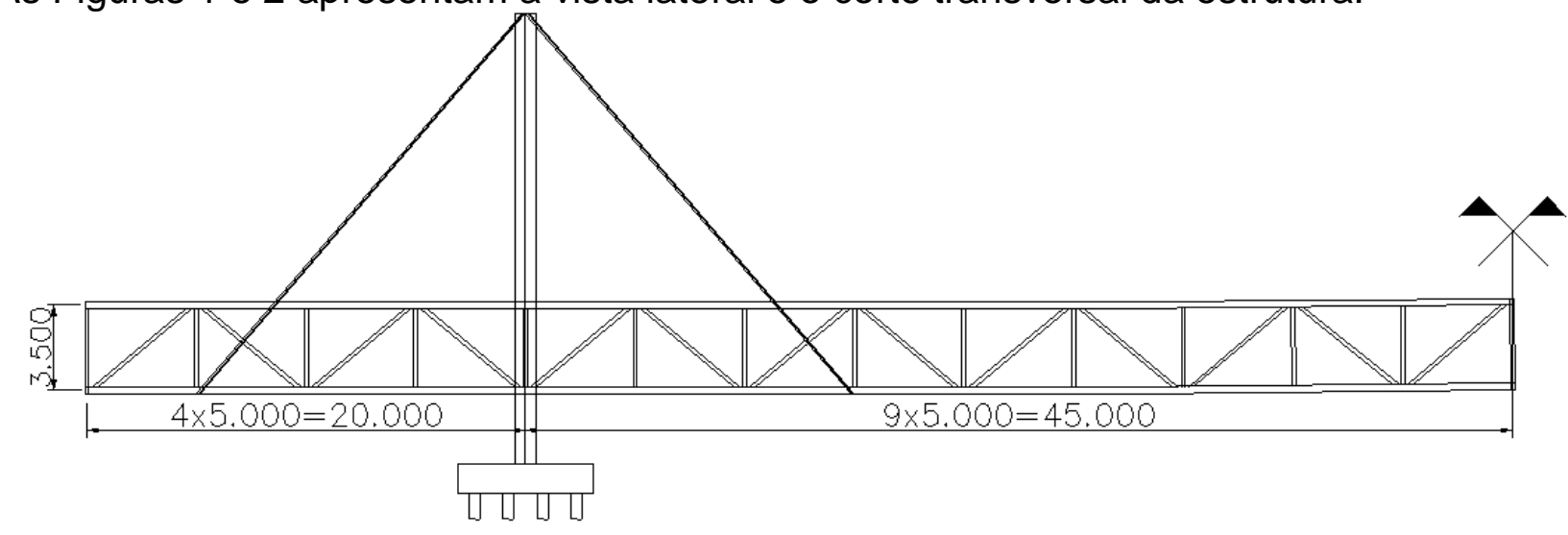

Figura 1 - Meia vista da estrutura existente.

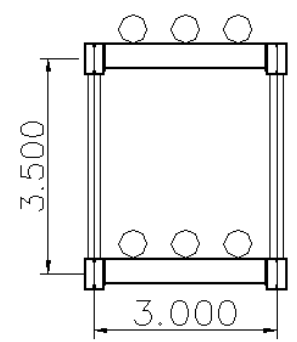

Figura 2 - Corte transversal da treliça.

\section{Apuração das causas do sinistro}

As fortes chuvas seguidas de vento que ocorreram no interior de São Paulo no ano de 2019, fizeram com que a estrutura ruísse. Porém, as causas primárias do desabamento deveriam ser diagnosticadas, para que não mais se caísse no mesmo erro. Desta forma procurou-se investigar as causas, adotando a seguinte metodologia:

- Pesquisa documental, onde seriam estudados os projetos existentes e confrontados com a estrutura in loco.

- Pesquisa documental, visando encontrar as possíveis intervenções realizadas na estrutura, através de relatórios de manutenção e relatórios fotográficos

- Levantamentos de campo, observando as condições da estrutura e o entorno da mesma

\subsection{Pesquisa documental}

A pesquisa documental obteve grande êxito, pois foram encontrados todos os projetos estruturais relativos à obra (fundação e estrutura metálica), com uma boa qualidade de detalhes, onde todos os itens constantes na estrutura estavam presentes. Infelizmente não se pode dizer o mesmo acerca da opção estrutural adotada, pois esta não era a melhor para o ambiente onde se encontrava instalada a treliça (área industrial altamente agressiva). 
Quanto à parte da documentação relativa às intervenções, nada fora fornecido e foi informado que desde a entrega da obra (há 20 anos) nada se faz, nem mesmo uma verificação do surgimento de algum possível ponto de corrosão e/ou alguma patologia de utilização.

\subsection{Levantamentos de campo}

Com as informações contidas nos projetos, mesmo com a estrutura sinistrada, pôde-se observar em campo as nuances e os detalhes estruturais, estando estes, em parte, de acordo com o que fora proposto pelo projeto. Muitas das peças apresentavam avançado estado de corrosão, sendo que em alguns pontos, havia corrosão generalizada, ficando parte da peça cortada. Quanto ao entorno o mesmo estava alterado devido à queda de diversas árvores sobre a estrutura e à presença de voçorocas que deixaram a mostra as estacas de um dos lados da ponte.

Após as primeiras análises, pôde-se afirmar com certeza de que a ruína teve as seguintes causas:

- Ausência de manutenção na estrutura

- Ausência de manutenção no entorno da ponte

- Material utilizado não condizente com o especificado no projeto

- Erros de fabricação e montagem.

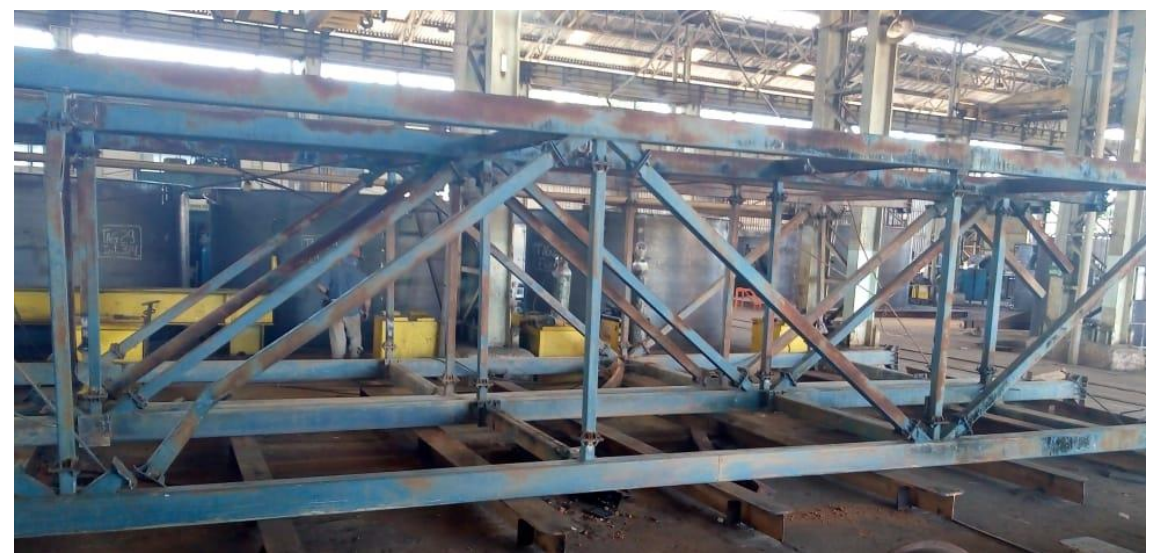

Figura 3 - Vista de parte da estrutura, com diversas regiões em avançado estado de corrosão.
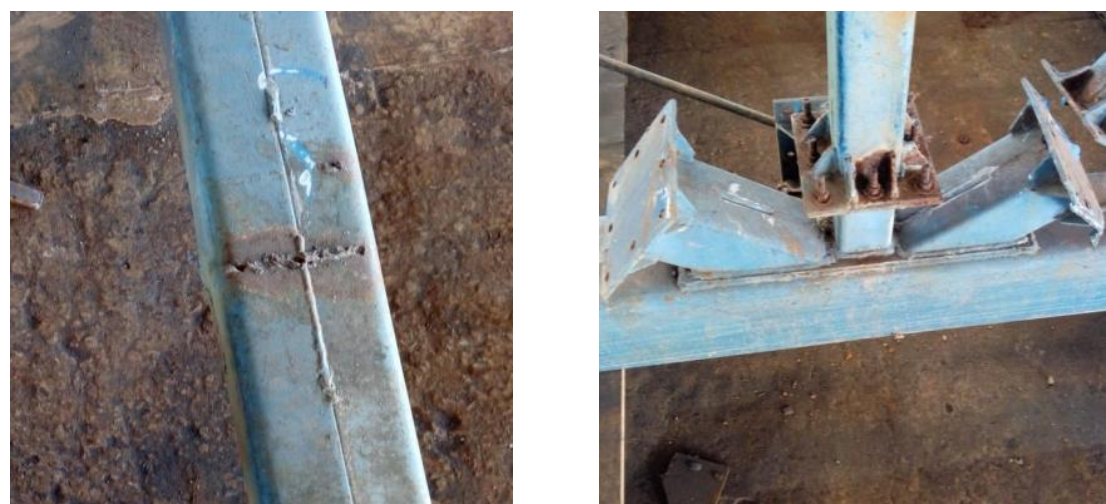

Figura 4 - À esquerda detalhe de peça onde ocorreu corrosão na solda. Observa-se a baixa qualidade da solda e ausência de acabamento. À direita parafusos de ligação em avançado estado de corrosão. 


\section{Proposta de reutilização estrutural}

Como boa parte das peças apresentava bom estado de conservação, foi proposto a utilização das peças como uma treliça isostática, alocada em um local onde o canal do rio tivesse menor largura e que as influências externas (árvores e agressividade ambiental) fosse de menor monta, de forma a impedir que um novo sinistro ocorresse. Optou-se pelo comprimento de $60 \mathrm{~m}$, como mostrado pela Figura 5.

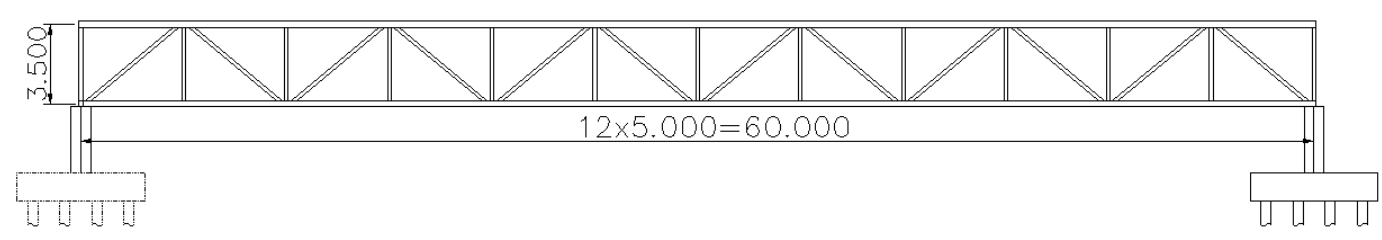

Figura 5 - Vista da nova estrutura, sem balanços, tirantes e com apenas o vão central.

De posse da necessidade da indústria (três tubos na parte superior e três tubos na parte inferior), das cargas de vento obtidas através da NBR 6123 (1) e de alguma carga para manutenção, partiu-se para o cálculo e detalhamento da nova estrutura. Para peças em perfis leves (dobrados a frio) utilizou-se a NBR14623 (2) e para os reforços em cantoneira e chapa grossa, NBR8800 (3).

Escolheram-se as melhores peças e através da engenharia reversa ficou patente a necessidade da colocação de reforços e, em alguns casos, troca das peças. Onde era necessária o aumento de área de aço, colocou-se uma chapa soldada na alma do perfil e onde poderia haver troca de sentido dos esforços, por segurança fora colocada uma nova diagonal, ficando assim o sistema composto por uma peça em "X".
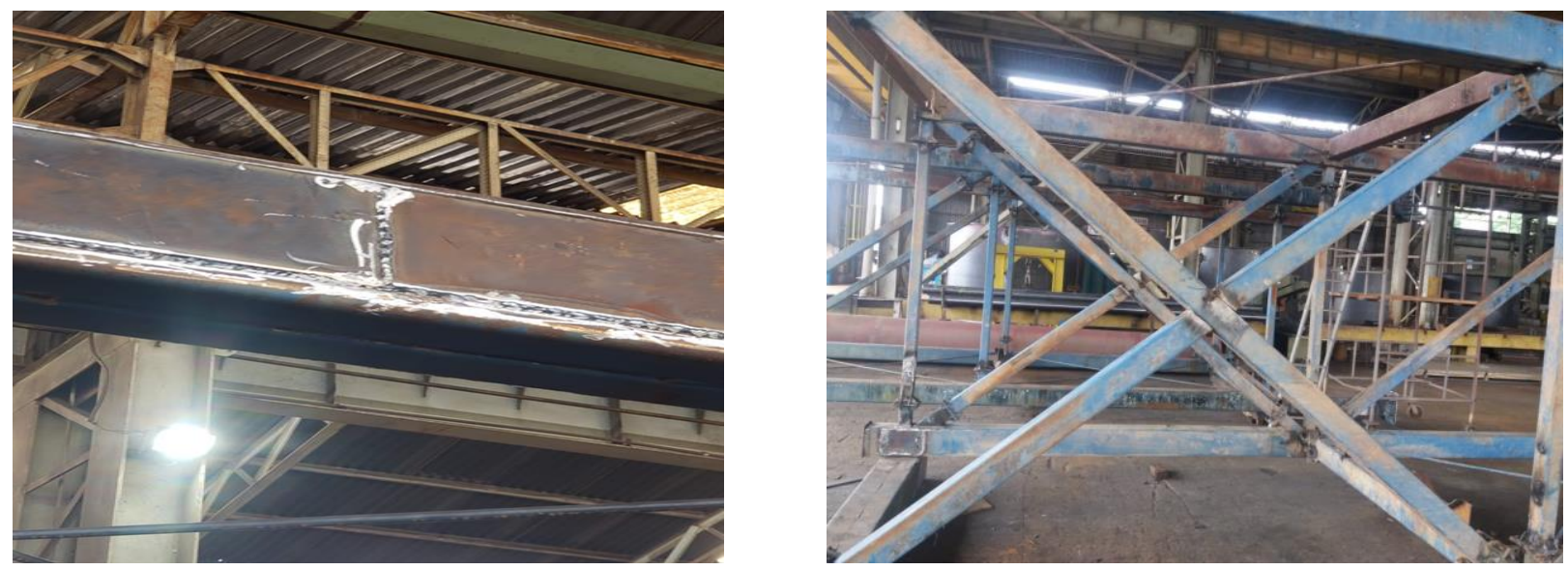

Figura 6 - À esquerda vista de um reforço em chapa grossa soldado à alma do perfil dobrado a frio. À direita, para diminuição do trabalho e aumento da segurança, foi colocado (próximo aos apoios) diagonais em " $X$ ".

\section{Conclusões}

Este estudo de caso permite afirmar que:

- Assim como os seres vivos, toda e qualquer edificação ou estrutura, deve ter a sua história registrada, pois em caso de algum acidente, se necessário realizar alguma intervenção, esta será mais fácil e mais econômica; 
- As estruturas têm que ser projetadas e construídas considerando o entorno das mesmas, verificando o tipo de ambiente em que a mesma será inserida e se existe a possibilidade da ocorrência de algum sinistro, quer seja provocado ou oriundo das forças da natureza;

- A reutilização de uma estrutura é viável, desde que a estrutura existente seja analisada com muito critério e que a proposta de reutilização seja bem estudada e levada a cabo com equipe capacitada e experiente;

- Independente da condição, toda e qualquer estrutura necessita de manutenção periódica, pois imprevistos podem acontecer sem prévio aviso.

- A fiscalização participativa deve ser uma constante, quer seja na fase de projeto, fabricação e montagem da estrutura metálica, não cessando após a entrega da obra.

\section{Referências}

[1] NBR 6123:1.988 - Cargas devidas ao vento em edificações. ABNT - Associação Brasileira de Normas Técnicas, 1.988. Rio de Janeiro.

[2] NBR 14762:2.010 - Dimensionamento de estruturas de aço constituídas por perfis formados a frio

[3]NBR 8800:2.008 - Projeto de estruturas de aço e de estruturas mistas de aço e concreto de edifícios, 2.008. Associação Brasileira de Normas Técnicas, 1.988. Rio de Janeiro. 